Lung (1996) 174:333-344

\title{
Effects of Vagal Stimulation on Slowly Adapting Pulmonary Stretch Receptors and Lung Mechanics in Anesthetized Rabbits
}

\author{
S. Matsumoto \\ Department of Physiology, Nippon Dental University, 1-9-20 Fujimi, Chiyoda-ku, Tokyo 102, Japan
}

\begin{abstract}
An in vivo preparation was designed to investigate the effect of vagus nerve stimulation-induced bronchoconstriction on the relationship of slowly adapting pulmonary stretch receptor (SAR) activity and lung mechanics. SAR activities were recorded from the left vagus nerve. The responses of SARs, total lung resistance $\left(R_{L}\right)$, and dynamic lung compliance $\left(C_{d y n}\right)$ to electrical stimulation of the peripheral end of the cut right vagus nerve $(10-15 \mathrm{~V}, 5-30 \mathrm{~Hz}, 0.2 \mathrm{~ms})$ were examined before atropine and 5 and $10 \mathrm{~min}$ after atropine $(2 \mathrm{mg} / \mathrm{kg})$ in anesthetized, artificially ventilated, bilaterally vagotomized rabbits. In the time course profile during vagal stimulation, an increase in $\mathrm{R}_{\mathrm{L}}$ and a decrease in $\mathrm{C}_{\text {dyn }}$ occurred simultaneously, and these opposite changes were frequency dependent. The average responses of SAR activity, $\mathrm{R}_{\mathrm{L}}$, and $\mathrm{C}_{\mathrm{dyn}}$ to vagal stimulation became more pronounced as the frequencies of the stimulation were increased. The responses obtained during vagal stimulation $(5-30 \mathrm{~Hz})$ were blocked or diminished greatly by the administration of atropine. Repeated vagus nerve stimulation in the presence of atropine did not show any significant change in SAR activity and lung mechanics. These results suggest that changes of $S A R$ activity, $R_{L}$, and $C_{\text {dyn }}$ induced by vagal stimulation occur as a result of smooth muscle contraction in the airways, which is mediated mainly by muscarinic receptor activation and which is not involved in the release of neurotranmitters to relax airway smooth muscle.
\end{abstract}

Key words: Slowly adapting pulmonary stretch receptor-Total lung resistanceDynamic lung compliance-Atropine-Vagally mediated bronchoconstriction

\section{Introduction}

Activation of efferent cholinergic fibers that innervate the airways and lungs and that travel in the vagus nerve results in bronchoconstriction mediated through the release of 
acetylcholine (ACh), which binds to muscarinic receptors on airway smooth muscle. Administration of bronchoconstrictive drugs is well known to stimulate the activity of vagal efferent fibers $[29,31]$. Thus, it can be assumed that bronchoconstrictor responses to various stimuli, i.e. electrical stimulation of the vagus nerve and administration of chemical substances, are modulated by the responsiveness of efferent activity in the vagus nerve. Concerning the bronchoconstrictor mechanism during vagal stimulation, there are species differences. For example, vagal stimulation in the guinea pig can promote the release of two different neurotransmitters such as ACh from efferent cholinergic nerves and neuropeptides (substance $\mathrm{P}$, neurokinin $\mathrm{A}$, and calcitonin generelated peptide) from capsaicin-sensitive nerves $[13,14]$. In the rabbit the bronchoconstriction evoked by vagal stimulation is mediated by the release of ACh [17].

Changes in parenchymal elasticity are known to be determined by both surface and tissue forces at the alveolar level. Administration of ACh into the pulmonary and/or bronchial circulation results in bronchoconstriction characterized by an increase in lung resistance and a simultaneous decrease in lung compliance, indicating that there may be a close interaction between airway contraction and lung compliance [5, 13, 19, 21].

On the other hand, slowly adapting pulmonary stretch receptors (SARs) are myelinated vagal afferent nerve terminals localized mainly in the smooth muscle of conducting airways. They have multiple properties, responding to mechanical and chemical stimuli and changes in tension across the airway wall, and they are responsible for the Hering-Breuer reflex and may regulate changes in bronchial tone during inspiration $[4,11,13]$. In addition, reduction in dynamic lung compliance $\left(C_{\text {dyn }}\right)$, caused by removing briefly the positive end-expiratory pressure (PEEP) in open chest cats with artificial ventilation, and bilateral vagotomy, elicits characteristic changes in SAR activity, and this effect is still observed after atropine to prevent a cholinergic contractile response [32]. Considering these observations, recording of the single unit activity of SARs is an effective way to investigate the relationship between the contraction of airway smooth muscle and lung elasticity.

The purpose of the present study was to determine whether or not changes of $C_{\text {dyn }}$ induced by vagally mediated bronchoconstriction are related to contractions of airway smooth muscle in in vivo experiments. Thus, the right vagus nerve was used for electrical stimulation; SARs were recorded from the left vagus nerve. Under these conditions, the responses of SAR activity, total lung resistance $\left(R_{L}\right)$, and $C_{d y n}$ to vagal stimulation at increasing frequencies $(5-30 \mathrm{~Hz})$ were examined before and after administration of atropine $(2 \mathrm{mg} / \mathrm{kg})$ in anesthetized, artificially ventilated, bilaterally vagotomized rabbits. In in vivo experiments using rabbit isolated tracheal segments, pretreatment with vasoactive intestinal peptide (VIP) inhibits the contractile responses to exogenous $\mathrm{ACh}$ and field electrical stimulation [9]. The results indicate that vagally mediated bronchoconstriction in the rabbit may be partly involved in the release of VIP, which inhibits the release of ACh from the parasympathetic nerve endings. To define whether or not vagal stimulation evokes the release of motor neuropeptidos such as VIP, additional experiments were designed to investigate the responses of SAR activity and lung mechanics $\left(\mathrm{R}_{\mathrm{L}}\right.$ and $\left.\mathrm{C}_{\mathrm{dyn}}\right)$ to vagal stimulation $(5-30 \mathrm{~Hz}$ ) before atropine and 5 and $10 \mathrm{~min}$ after atropine $(2 \mathrm{mg} / \mathrm{kg})$, and those responses were compared. 


\section{Materials and Methods}

Sixteen rabbits, weighing $2.5-3.5 \mathrm{~kg}$, were anesthetized with urethane $(1 \mathrm{~g} / \mathrm{kg})$ given intraperitoneally. Supplemental doses $(0.1-0.2 \mathrm{~g} / \mathrm{kg} / \mathrm{h}$, intravenous) of this anesthetic agent were administered from a polyethylene catheter inserted into the femoral vein. The trachea was cannulated, and a polyethylene catheter was inserted into the femoral artery for measurement of systemic arterial blood pressure (SAP) and also placed in the right atrium through the external jugular vein for administration of drugs or a $0.9 \% \mathrm{NaCl}$ solution (saline). The superior laryngeal and recurrent laryngeal nerves were sectioned in advance. The trachea and esophagus were retracted rostrally to obtain space for paraffin pool. Then, the vagus nerves were identified and sectioned.

Following intramuscular administration of suxamethonium $(10 \mathrm{mg} / \mathrm{kg})$, animals were artificially ventilated. Additional doses of this muscular relaxant were maintained with a constant infusion at $10 \mu \mathrm{g} / \mathrm{kg} / \mathrm{min}$. The stroke volume of the respirator was set at $10 \mathrm{ml} / \mathrm{kg}$, and its frequency ranged from 30 to 35 cycles $/ \mathrm{min}$. Tracheal $\mathrm{CO}_{2}$ pressure was monitored and kept at $32-35 \mathrm{mmHg}$ by adjusting the ventilatory rate.

Respiratory airflow $(\dot{V})$ was measured by connecting the tracheal tube to a pneumotachograph and a differential transducer (Sanei MP245), and their flow signal was integrated by means of an integrator to record tidal volume $\left(\mathrm{V}_{\mathrm{T}}\right)$. Tracheal pressure $\left(\mathrm{P}_{\mathrm{T}}\right)$ was measured by connecting a polyethylene catheter inserted into the tracheal tube to a differential transducer, in which one arm opened to the atmosphere. $R_{L}$ and $\mathrm{C}_{\mathrm{dyn}}$ were calculated using a manual graphic method reported by Norlander et al. [25].

The peripheral end of the cut left vagus nerve was desheathed. A thin filament containing afferent nerve fibers was separated, placed on a unipolar silver electrode, and submerged under warm liquid paraffin $\left(37-38^{\circ} \mathrm{C}\right)$. The small filament was split until the single unit activity of SARs had been electrically identified. Afferent impulses of SARs were confirmed on the basis of their characteristic firing patterns during lung inflation: (1) The SARs fired throughout the whole respiratory cycle. (2) The SARs increased their activity proportionally as the volume of the respirator was increased. (3) The SAR activity continued as long as the tracheal tube was occluded in a hyperinflated condition. Location of the receptors was determined using a small ballon catheter [19-21]. Ten SARs located below the carina were obtained in ten rabbits. The action potentials of SARs were selected by a window discriminator counting the number of impulses of a single unit activity, monitored on an oscilloscope and recorded on a polygraph.

The end of the cut right vagus nerve was desheathed in a paraffin pool and placed on the stimulating electrodes. To prevent the electrical noise due to vagal stimulation, the stimulating electrodes were surrounded by a rubber sheet. The vagus nerve was stimulated at $10-15 \mathrm{~V}, 5-30 \mathrm{~Hz}$, and $0.2 \mathrm{~ms}$ for approximately $30 \mathrm{~s}$.

In ten different SARs in ten rabbits, the effect of vagal stimulation at increasing frequencies $(5,10,20$, and $30 \mathrm{~Hz}$ ) on $\mathrm{SAR}$ activity, $\mathrm{R}_{\mathrm{L}}$ and $\mathrm{C}_{\mathrm{dyn}}$ was determined. After confirming no significant effect on vagal stimulation $(30 \mathrm{~Hz})$, the same tests were repeated $5 \mathrm{~min}$ after administration of atropine $(2 \mathrm{mg} / \mathrm{kg}$, intravenously).

In the time course profile of lung mechanics during vagal stimulation, the control responses of $\mathrm{R}_{\mathrm{L}}$ and $\mathrm{C}_{\mathrm{dyn}}$ were measured for $3 \mathrm{~s}$ before vagal stimulation and expressed as $100 \%$. The changes of $\mathrm{R}_{\mathrm{L}}$ and $\mathrm{C}_{\mathrm{dyn}}$ induced by vagal stimulation $(5-30 \mathrm{~Hz})$ before and after atropine administration $(2 \mathrm{mg} / \mathrm{kg})$ were measured at 3-s intervals for $30 \mathrm{~s}$, and their respective change was expressed as a percent change from the control values.

Additional experiments were performed on six different SARs in six rabbits. The effects of vagal stimulation with different frequencies $(5-30 \mathrm{~Hz})$ on SAR activity, $\mathrm{R}_{\mathrm{L}}$, and $\mathrm{C}_{\mathrm{dyn}}$ were determined. The same tests were repeated 5 and $10 \mathrm{~min}$ after administration of atropine $(2 \mathrm{mg} / \mathrm{kg}$, intravenously).

In two experiments during control conditions the average activities of SARs were measured over $10 \mathrm{~s}$. Average values of $R_{L}$ and $C_{d y n}$ were also calculated. The average activities of the receptors were expressed as impulses/s, and the average values of $R_{L}$ and $C_{d y n}$ were also expressed as $100 \%$. The responses of SARs to vagal stimulation $(5-30 \mathrm{~Hz})$ for $30 \mathrm{~s}$ were obtained by counting all action potentials from the onset of increased activity until the recovery to the control level, and the average activities of the receptors at each stimulus frequency were expressed as impulses/s. Similarly, the average values of $R_{L}$ and $C_{d y n}$ were expressed as percent changes from control values.

All values were expressed as means \pm S.E. The statistical significance of the effects of intravenous 
atropine $(2 \mathrm{mg} / \mathrm{kg})$ on the time course responses of $\mathrm{R}_{\mathrm{L}}$ and $\mathrm{C}_{\mathrm{dyn}}$ to vagal stimulation $(5-30 \mathrm{~Hz})$ was calculated using a paired Student's $t$ test. Statistical significance of the effects of atropine and vagal stimulation in the presence of atropine on the average responses of $R_{L}, C_{d y n}$, and SAR activity to vagal stimulation was calculated using a two-way analysis of variance (ANOVA). A $p$ value of less than 0.05 was considered statistically significant.

\section{Results}

Figure 1 shows typical examples of the responses of SAR activity, $\mathrm{P}_{\mathrm{T}}, \mathrm{V}_{\mathrm{T}}, \dot{\mathrm{V}}$, and SAP to vagal stimulation $(13 \mathrm{~V}, 10$ and $30 \mathrm{~Hz})$ before and after administration of atropine $(2 \mathrm{mg} / \mathrm{kg})$ in a rabbit. After the onset of vagal stimulation $(10 \mathrm{~Hz})$ the discharge of SARs during both inflation and deflation increased. Afterward the magnitude of increased inspiratory SAR activity became more pronouned in association with an increase in $\mathrm{P}_{\mathrm{T}}$. The response was usually associated with a decrease in heart rate (HR) (Fig. 1A). When the frequency of vagal stimulation was increased to $30 \mathrm{~Hz}$, the magnitudes of bronchoconstriction (measured as the increase in SAR activity and the decreases in $\dot{\mathrm{V}}$ and $\mathrm{V}_{\mathrm{T}}$ ) and bradycardia became more prominent (Fig. 1B). In the same animal, atropine treatment blocked the characteristic responses of SAR activity, $\mathrm{P}_{\mathrm{T}}$ and HR to vagal stimulation under the same stimulus conditions (Fig. 1,C and $D$ ).

The responses of $R_{L}$ and $C_{d y n}$ to vagal stimulation (5-30 Hz) in the absence and presence of atropine $(2 \mathrm{mg} / \mathrm{kg})$ are summarized in Figure 2, particularly in terms of time course profile. Vagal stimulation led to an increase in $R_{L}$ but a decrease in $C_{d y n}$, and there were more pronounced effects as the frequencies were increased. The occurrence of an $R_{L}$ increase seen during vagal stimulation was usually associated with a simultaneous decrease in $\mathrm{C}_{\mathrm{dyn}}$, and these opposite effects were frequency dependent. The time course responses of $\mathrm{R}_{\mathrm{L}}$ and $\mathrm{C}_{\mathrm{dyn}}$ to vagal stimulation at increasing frequencies were reduced significantly by pretreatment with atropine.

The average responses of SAR activity, $R_{L}$ and $C_{d y n}$ to vagal stimulation (5-30 $\mathrm{Hz}$ ) before and after administration of atropine in ten animals are summarized in Figure 3. The basal discharge of SARs in the control was $76.5 \pm 5.8 \mathrm{imp} / \mathrm{s}$. Baseline $R_{L}$ was $17.7 \pm 3.5 \mathrm{cmH}_{2} \mathrm{O} / \mathrm{liter} / \mathrm{s}$, and $\mathrm{C}_{\mathrm{dyn}}$ was $2.9 \pm 0.4 \mathrm{ml} / \mathrm{cmH}_{2} \mathrm{O}$. Vagal stimulation caused an increase in both SAR activity and $\mathrm{R}_{\mathrm{L}}$ and a decrease in $\mathrm{C}_{\mathrm{dyn}}$, and these effects were frequency dependent. Atropine treatment that had no effect on basal values of $R_{L}, C_{d y n}$, and SAR activity significantly diminished the bronchoconstrictions evoked by vagal stimulation at increasing frequencies.

The average responses of SAR activity, $\mathrm{R}_{\mathrm{L}}$, and $\mathrm{C}_{\mathrm{dyn}}$ to vagal stimulation (5-30 $\mathrm{Hz})$ in six animals before atropine as well as 5 and $10 \mathrm{~min}$ after atropine $(2 \mathrm{mg} / \mathrm{kg})$ are summarized in Figure 4. The basal discharge of SARs before atropine was 78.8 \pm 5.6 imp/s. Basal $\mathrm{R}_{\mathrm{L}}$ was $18.2 \pm 3.9 \mathrm{cmH}_{2} \mathrm{O} / \mathrm{liter} / \mathrm{s}$, and $\mathrm{C}_{\mathrm{dyn}}$ was $2.8 \pm 0.4 \mathrm{ml} / \mathrm{cmH}_{2} \mathrm{O}$. Increases in $\mathrm{SAR}$ activity and $\mathrm{R}_{\mathrm{L}}$ and reduction in $\mathrm{C}_{\mathrm{dyn}}$ occurred during vagal stimulation, and these effects were frequency dependent. Atropine treatment significantly suppressed the bronchoconstrictor responses to vagal stimulation $(5-30 \mathrm{~Hz})$, and the responses obtained at this period were not significantly different from the responses of SAR activity, $\mathrm{R}_{\mathrm{L}}$, and $\mathrm{C}_{\mathrm{dyn}}$ to the same stimuli after $10 \mathrm{~min}$ of atropine administration. 

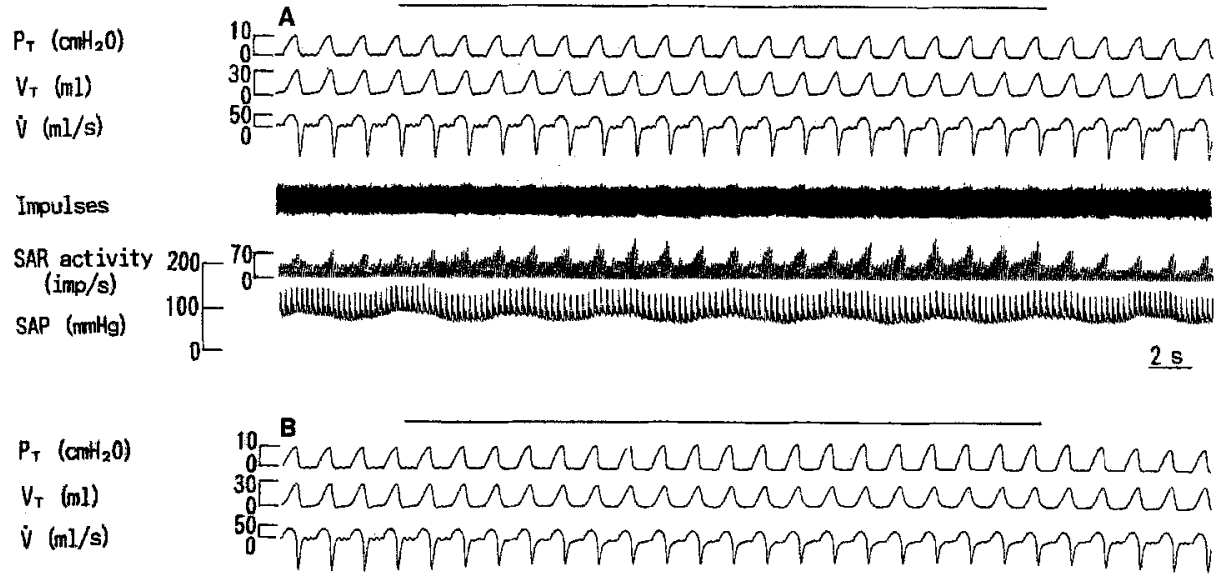

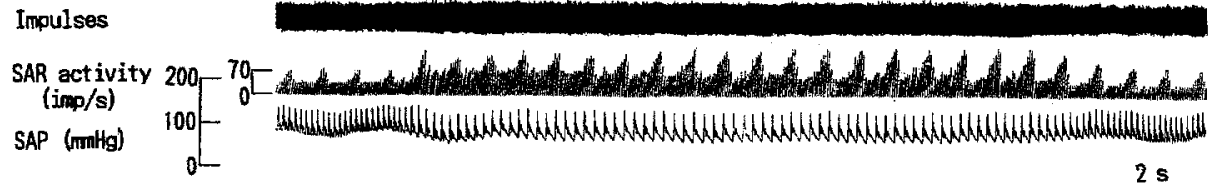

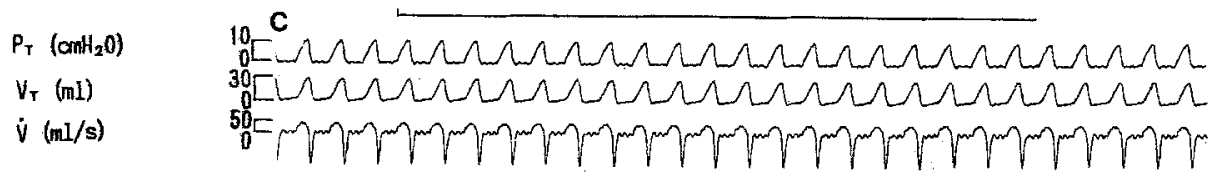

Impulses

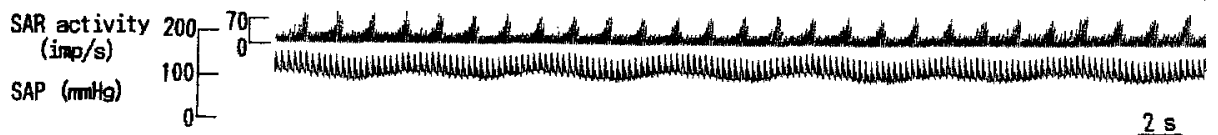

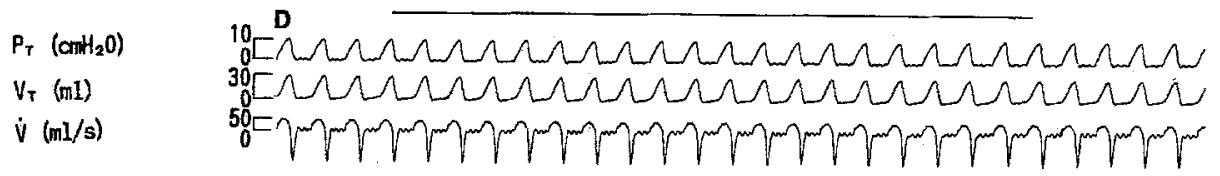

Impulses

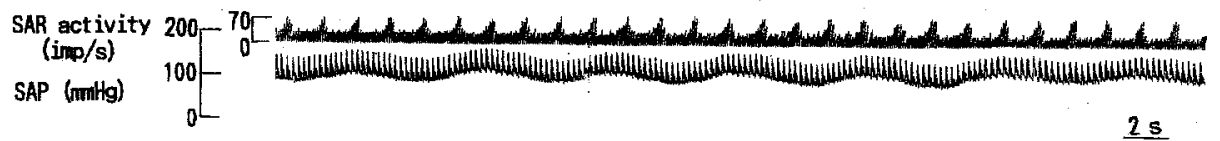

Fig. 1. Responses in $S A R$ activity, $R_{T}, V_{T}, V$, and $S A P$ to vagal stimulation (-) before and after administration of atropine. A, Vagal stimulation $(10 \mathrm{~Hz})$ before atropine $(2 \mathrm{mg} / \mathrm{kg})$. B, vagal stimulation $(30$ $\mathrm{Hz}$ ) before atropine $(2 \mathrm{mg} / \mathrm{kg})$. C, vagal stimulation $(10 \mathrm{~Hz})$ after atropine $(2 \mathrm{mg} / \mathrm{kg})$. D, vagal stimulation $(30 \mathrm{~Hz})$ after atropine. 


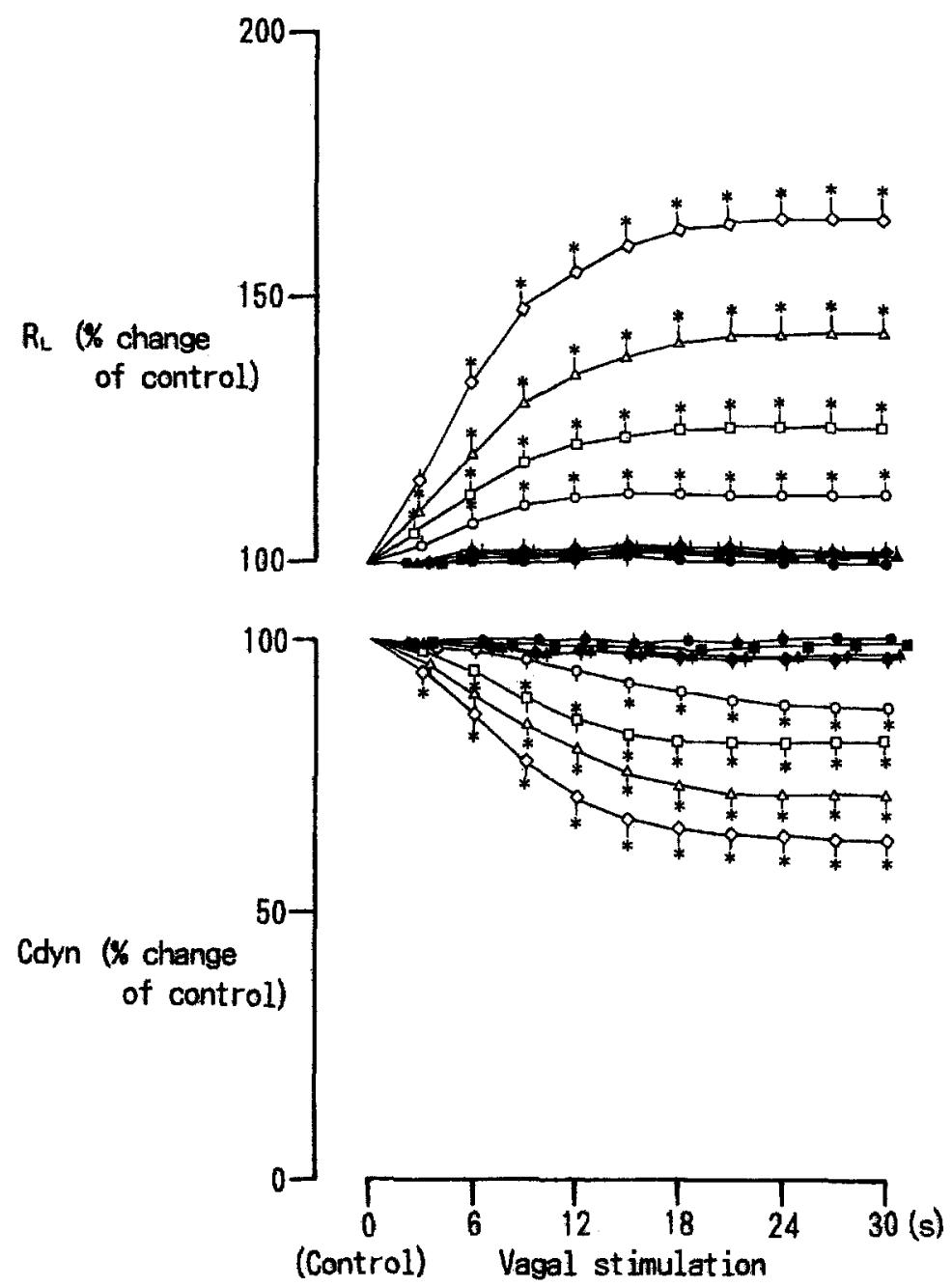

Fig. 2. Time course changes of $R_{L}$ and $C_{d y n}$ induced by vagal stimulation $(5,10,20$, and $30 \mathrm{~Hz})$ before and after administration of atropine $(2 \mathrm{mg} / \mathrm{kg}) .0,5 \mathrm{~Hz}$ before atropine;, $5 \mathrm{~Hz}$ after atropine; $\square, 10 \mathrm{~Hz}$ before atropine; $\mathbf{\square}, 10 \mathrm{~Hz}$ after atropine; $\triangle, 20 \mathrm{~Hz}$ before atropine; $\Delta, 20 \mathrm{~Hz}$ after atropine; $\diamond, 30 \mathrm{~Hz}$ before atropine; $\diamond, 30 \mathrm{~Hz}$ after atropine. Bars are means \pm S.E. $(n=10)$. *, statistical significance from the atropine effects.

\section{Discussion}

Electrical stimulation of the cut vagus nerve results in contractions of the airway smooth muscle, which appear to be cholinergic $[17,24]$ and/or noncholinergic $[1,13]$. A noncholinergic pathway mediated by the release of neuropeptides has been reported in guinea pigs $[7,10,14,28]$. Although the origin of noncholinergic innervation has not been elucidated, contractions of the airway smooth muscle are known to be sensitive to capsaicin and substance $\mathrm{P}$ antagonists $[10,14,28]$. Vagally induced noncholinergic 


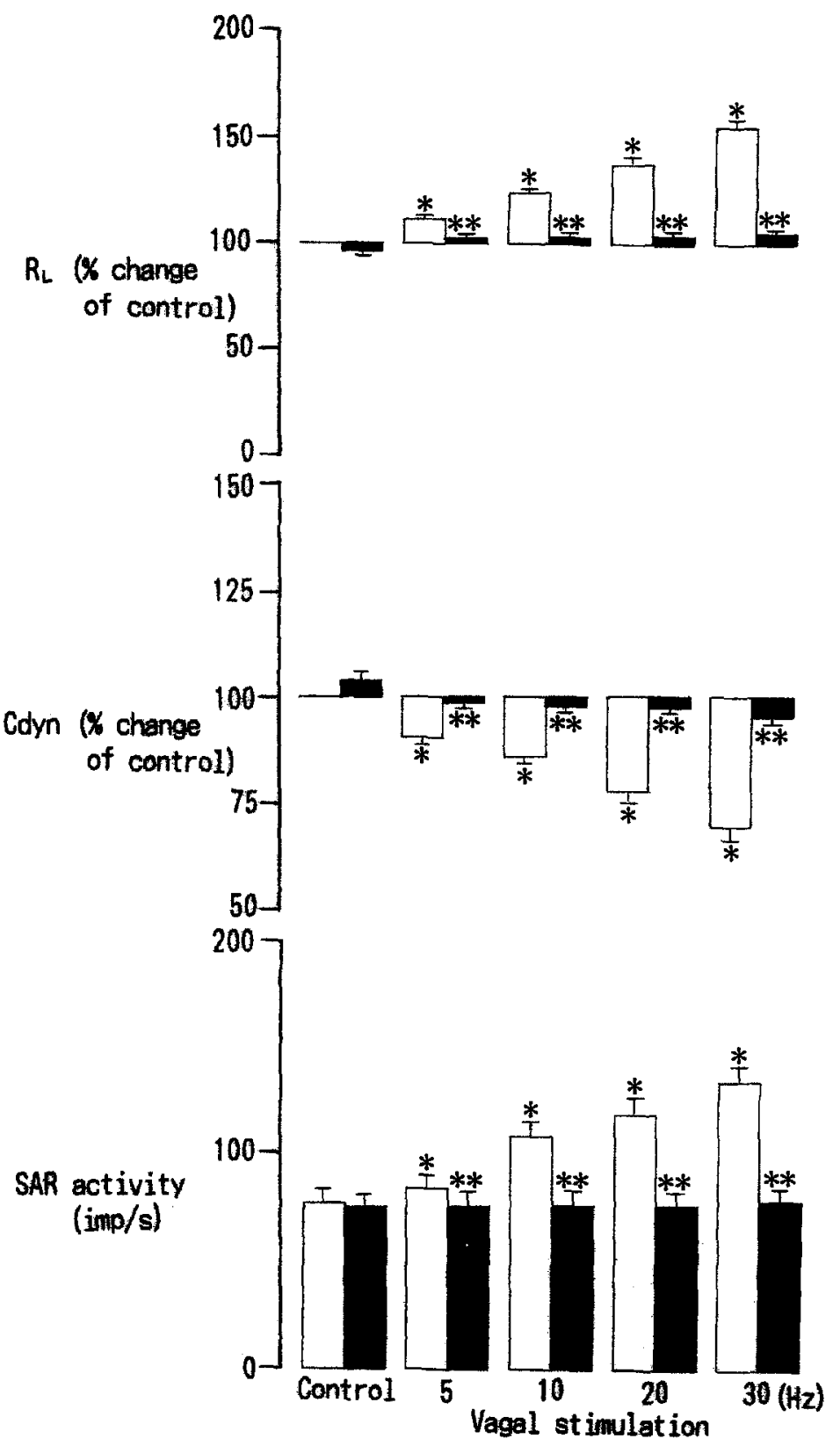

Fig. 3. Average changes of $S A R$ activity, $R_{L}$, and $C_{\text {dyn }}$ induced by vagal stimulation (5-30 Hz) before (open columns) and after (closed columns) administration of atropine $(2 \mathrm{mg} / \mathrm{kg})$. Vertical bars are means \pm S.E. ( $n$ $=10)$. *, Statistical significance from the control values. $* *$, statistical significance from the atropine effect. 


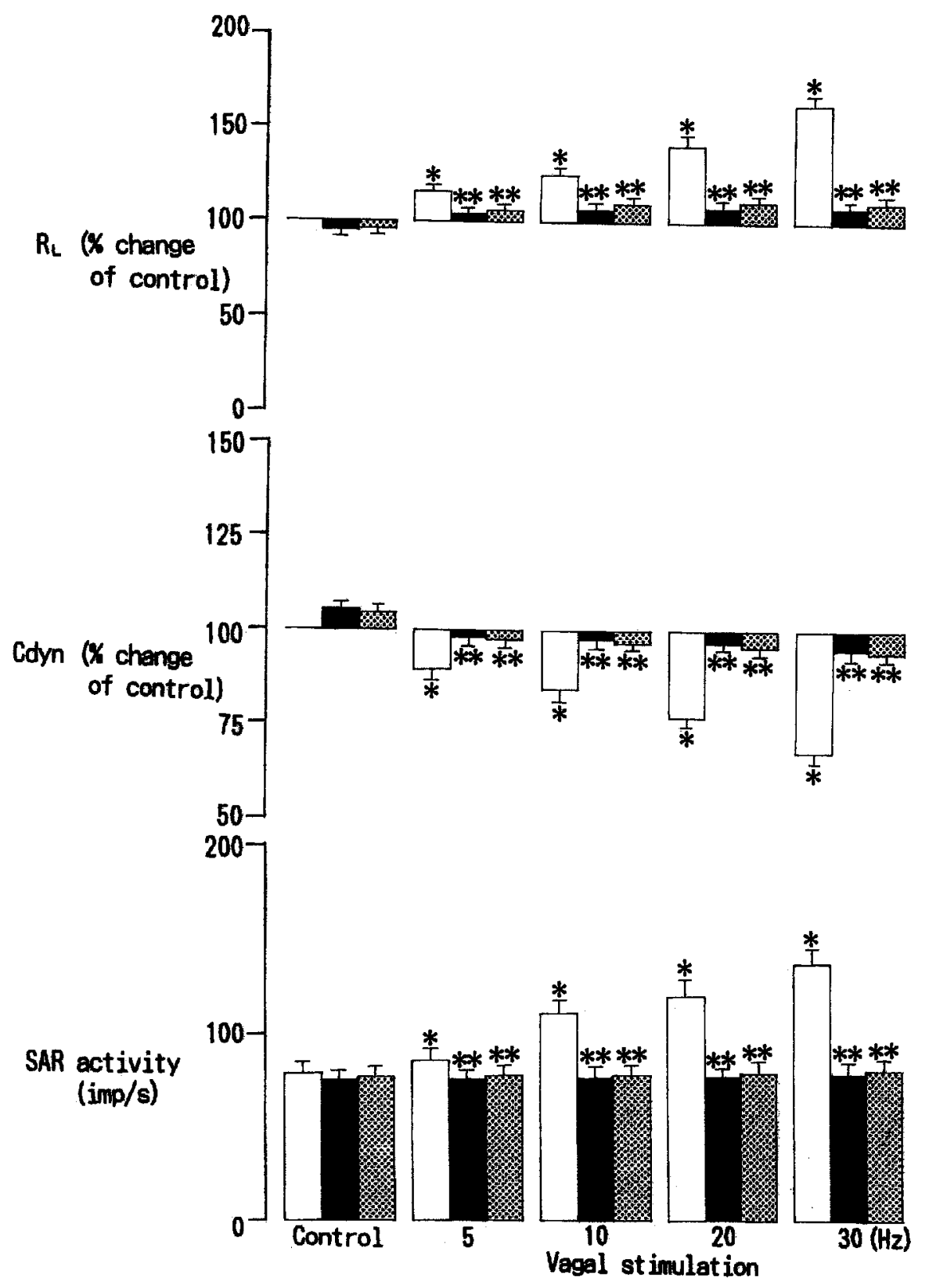

Fig. 4. Average changes of $S A R$ activity, $R_{L}$, and $C_{d y n}$ induced by vagal stimulation (5-30 $\mathrm{Hz}$ ) before atropine $(\square)$ and $5(\mathbf{D})$ and $10(\because)$ min after atropine $(2 \mathrm{mg} / \mathrm{kg})$. Vertical bars are means \pm S.E. $(n=6)$. *, statistical significance from the control values. **, statistical significance from the atropine effect. 
contraction is supported further by evidence that administration of atropine produces a partial blockade of the bronchoconstriction evoked by vagal stimulation, and the remaining effect of contraction is blocked by capsaicin treatment [13]. In the rabbit, an increase of tracheal pressure induced by vagal stimulation at $10 \mathrm{~Hz}$ in in vivo experiments is blocked by atropine [17]. The fact that atropine blocks the responses of SAR activity, $R_{L}$, and $C_{\text {dyn }}$ to vagal stimulation at 5-30 Hz leads to the suggestion that the bronchoconstriction evoked by vagal stimulation is not due to antidromic release of tackykinins from sensory nerves. This may be a difference from other species, such as guinea pigs. In rabbit isolated tracheal segments, using electrical field stimulation (EFS), VIP is capable of inhibiting vagally mediated bronchoconstriction. In isolated rabbit bronchus with intact vagal innervation, vagus nerve stimulation-induced contractions are abolished by atropine, and after cessation of repeated stimuli, the bronchus does not relax below the baseline level [2]. This difference raises the possibility that the EFS-induced relaxations are derived from nonvagal sources. In in vivo preparations, repeated vagus nerve stimulation in the presence of atropine that could block vagally mediated bronchoconstriction did not show any change in the measured parameters of airway smooth muscle relaxation. Thus, it seems reasonable to suggest that vagal stimulation that results in vigorous cholinergic contractions does not relax the atropinetreated rabbit airways. Thus, vagally mediated bronchoconstriction in the rabbit may not be involved in the contribution of noncholinergic influences.

If the right vagus stimulation-induced bronchoconstriction produces a decrease in lung compliance, reduced ventilation of the right lung would cause an increase in the SAR activity at the recording site. However, atropine has no significant effect on the SAR response to hyperinflation (unpublished observations), and an increase in tidal volume tends to decrease the SAR activity during deflation [21]. Considering these observations it can be suggested that some efferent fibers in the right vagus nerve may travel in the left vagus nerve and innervate the smooth muscle in the left lung.

The changes in $\mathrm{C}_{\mathrm{dyn}}$ are considered to represent an effect on alveolar surface, and both surface and tissue forces at the alveolar level are known to control parenchymal elasticity. Comparison of the responses elicited by aerosol application of bronchoconstrictor agents reveals that an increase in the peak discharge of SARs is related to a concomitant decrease in $\mathrm{C}_{\text {dyn }}$ rather than an increase in the airway resistance [30]. Although intrapulmonary stretch receptors are distributed mainly on the walls of conducting airways [26], by simultaneous analysis of the single unit activity of SARs in relation to changes in lung mechanics it is possible to differentiate between the influence of $R_{L}$ and $C_{d y n}$ to a given bronchoconstriction. Indeed, there is evidence that reduction in $C_{\text {dyn }}$ during brief removal of PEEP causes a significant decrease in the SAR activity during deflation but slightly augments their activity during inflation in open chest cats with both artificial ventilation and PEEP [32]. Under these conditions, atropine treatment that prevents contractions of the airway smooth muscle has no effect on the responses of SAR activity and $P_{T}$ to reduced $C_{d y n}$ [32]. Under similar experimental conditions reported by $\mathrm{Yu}$ et al. [32] in the cat, isoprenaline, a potent bronchodilator, blocks the increases of SAR activity and $\mathrm{P}_{\mathrm{T}}$ induced by histamine administration but does not significantly alter those responses to reduced $\mathrm{C}_{\text {dyn }}$ in artificially ventilated rabbits with PEEP [19]. From these observations, administration of cholinergic blockers and/or bronchodilators does not block the characteristic responses of 
SAR activity to reduction in $\mathrm{C}_{\mathrm{dyn}}$. In the present experiments recorded with SAR activity, vagal stimulation increased both the receptor activity and $R_{L}$ but decreased $\mathrm{C}_{\mathrm{dyn}}$. These changes became more prominent, as the stimulus frequencies were increased to 5-30 Hz. In addition, prior treatment with atropine significantly inhibited the responses of $S A R$ activity, $R_{L}$, and $C_{d y n}$ to vagal stimulation at $5-30 \mathrm{~Hz}$. The difference in the SAR responses to reduced $\mathrm{C}_{\mathrm{dyn}}$ compared with the results of $\mathrm{Yu}$ et al. [32] may be due to the species differences and/or the difference of location of the receptors recorded. When considering these observation and results obtained in the present study, it is likely that the mechanism of reduced $\mathrm{C}_{\mathrm{dyn}}$ during vagus nerve stimulation-induced bronchoconstriction is different from that seen after briefly removing PEEP.

Intravenous administration of bronchoconstrictive agents is known to elicit increases in $R_{L}$ associated with simultaneous decrease in $C_{\text {dyn }}$. In preparations with selective perfusion of the bronchial circulation or with selective administration into the bronchial artery, bronchoconstrictive agents caused an increase in $\mathrm{R}_{\mathrm{L}}$ and a simultaneous decrease in $C_{d y n}[5,16,23]$. In experiments that examine the selectivity of airway responses elicited by $\mathrm{ACh}$ infusion of the pulmonary and bronchial circulations, an increase in $R_{L}$ is usually associated with a simultaneous decrease in $C_{\text {dyn }}$, and this opposite effect is dose dependent for ACh. Intravenous administration of atropine blocks changes of lung mechanics in response to ACh injection [22]. This implies that there is a homogeneity in response to $\mathrm{ACh}$ between the central and peripheral airway. In this study, changes in lung mechanics (an increase in $\mathrm{R}_{\mathrm{L}}$ and a decrease in $\mathrm{C}_{\text {dyn }}$ ) occurred almost simultaneously in the time course profile during vagal stimulation, and these changes were inhibited significantly by atropine treatment. Considering the average responses of SAR activity, $R_{L}$, and $C_{d y n}$ to vagal stimulation before and after atropine, the decrease in $\mathrm{C}_{\mathrm{dyn}}$ is probably mediated by contractions of the smooth muscle in the conducting airways. However, we cannot rule out the possibility that the bronchoconstrictions evoked by pharmacologic and physiologic stimuli are heterogeneously distributed in the bronchopulmonary tree $[5,16,22,23]$. Using the technique of bronchial artery perfusion in the sheep, Mitzner et al. [22] reported that a decrease in $\mathrm{C}_{\mathrm{dyn}}$ occurred with a constant infusion of methacholine ( $\mathrm{MCh}, 2.4 \mu \mathrm{g} / \mathrm{min}$ ) into the bronchial circulation, whereas the same infusion rate of $\mathrm{MCh}$ into the pulmonary circulation had no significant effect on $\mathrm{C}_{\mathrm{dyn}}$. These results indicate that the conducting airways may have a major role in regulating lung elasticity. However, in the rabbit there are no studies to determine at what size airways are supplied primarily by the bronchial circulation and whether or not there is anastomosis between bronchial and pulmonary circulations.

\section{References}

1. Barnes PJ (1986) Neural control of human airways in health and disease. Am Rev Respir Dis 134: 1289-1314

2. Bloom JW, Baumgartener-Folkerts C, Palmer JD, Yamamura HI, Halonen M (1988) A muscarinic receptor subtype modulates vagally stimulated bronchial contraction. J Appl Physiol 65:2144-2150

3. Charan NB, Turk GM, Dhand R (1984) Gross and subgross anatomy of brochial air culation in sheep. J Appl Physiol 57:658-664 
4. Coleridge HM, Coleridge JCG (1986) Reflexes evoked from the tracheobronchial tree and lungs. In: Cherniack NS, Widdicombe JG (eds) Handbook of Physiology, Section 3. The Respiratory System. Vol. 2, Part 2. Control of Respiration. American Physiological Societý, Washington, D.C., pp 395-429

5. DeKock MA, Nadel JA, Zwi S, Colebatch HJH, Olsen CR (1966) New method for perfusing bronchial arteries: histamine bronchoconstriction and apnea. J Appl Physiol 21:185-194

6. Drazen JM, Schneider MW (1977) Comparative response of tracheal spiral and parenchymal strips to histamine and carbachol. J Clin Invest 61:1441-1447

7. Grundström N, Andersson RGG, Wikberg JES (1981) Pharmacological characterization of the autonomic innervation of the guinea pig tracheobronchial smooth muscle. Acta Pharmacol Toxicol 49:150-157

8. Hendrix SG, Munoz NM, Leff AR (1983) Physiological and pharmacologic response of canine bronchial smooth muscle in situ. J Appl Physiol 54:215-224

9. Kanemura T, Tamaoki J, Chiyotani A, Takeyama K, Sakai N, Tagaya E, Konno K (1993) Role of $\mathrm{Na}^{+}-\mathrm{K}^{+}$ATPase in airway smooth muscle relaxation by vasoactive intestinal and pituitary adenylate cyclase activating peptide. Res Commun Chem Pathol Pharmacol 79:11-22

10. Karlsson J-A, Finney MJB, Persson CGA, Post C (1984) Substance P antagonists and the role of tachykinins in noncholinergic bronchoconstriction. Life Sci 35:2681-2691

11. Karlsson J-A, Sant'Ambrogio G, Widdicombe J (1988) Afferent neural pathways in cough and reflex bronchoconstriction. J Appl Physiol 65:1007-1023

12. Leff AR, Munoz NM, Alderman B (1982) Measurement of airway response by isometric and nonisometric techniques in situ. J Appl Physiol 52:1363-1367

13. Lundberg JM, Saria A (1982) Bronchial smooth muscle contraction induced by stimulation of capsaicinsensitive sensory neurons. Acta Physiol Scand 116:473-476

14. Lundberg JM, Saria A (1983) Neurogenic inflammation and capsaicin-sensitive substance $P$ neurons with special reference to the respiratory tract. Acta Physiol Scand 119:243-252

15. Magno MG, Fishman AP (1982) Origin, distribution, and blood flow of bronchial circulation in anesthetized sheep. J Appl Physiol 53:272-279

16. Martinez L, De Letona J, Castro de la Mata R, Aviado DM (1961) Local and reflex effects of bronchial aterial injection of drugs. J Pharmacol Exp Ther 133:295-303

17. Matsumoto S, Nagayama T, Kanno T, Yamasaki M, Shimizu T (1995) Evidence for the presence of function of the inhibitory $\mathrm{M}_{2}$-receptors in the rabbit airways and lungs. J Auton Nerv Syst 53:126-136

18. Matsumoto S, Nagayama T, Yamasaki M, Kanno T, Shimizu T (1992) Cholinergic and $\mathrm{H}_{1}$-receptor influences of histamine on slowly adapting pulmonary stretch receptor activity in the rabbit. $\mathbf{J}$ Auton Nerv Syst 40:107-120

19. Matsumoto S, Shimizu T (1994) Effects of isoprenaline on the responses of slowly adapting pulmonary stretch receptors to reduced lung compliance and to administered histamine. Neurosci Lett 172:47-50

20. Matsumoto S, Shimizu T, Kanno T, Yamasaki M, Nagayama T (1990) Effects of histamine on slowly adapting pulmonary stretch receptor activities in vagotomized rabbits. Jpn J Physiol 40:737-752

21. Matsumoto S, Yamasaki M, Kanno T, Nagayama T, Shimizu T (1993) Effects of calcium channel and $\mathrm{H}_{1}$-receptor blockers on the responses of slowly adapting pulmonary stretch receptors to histamine in vagotomized rabbits. Lung 171:1-13

22. Mitzner W, Blosser S, Yager D, Wagner E (1992) Effect of bronchial smooth contraction on lung complicance. J Appl Physiol 72:158-167

23. Munoz NM, Chang S-W, Murphy TM, Stimler-Gerard NP, Blake J, Mack M, Irvin C, Voelkel NF, Leff AR (1989) Distribution of bronchoconstrictor response in isolated-perfused rat lung. J Appl Physiol 66:202-209

24. Nadel JA (1980) Autonomic regulation of airway smooth muscle. In: Nadel JA (ed) Physiology and Pharmacology of the Airways, New York, Dekker, pp 217-257

25. Norlander O, Herzog P, Norden I, Hossli G, Schaer H, Gattiker R (1968) Compliance during airway resistance during anaesthesia with controlled ventilation. Acta Anaesth Scand 12:135-152

26. Sant'Ambrogio G (1982) Information arising from the tracheobronchial tree of mammals. Physiol Rev 62:531-569

27. Shioya T, Pollack ER, Munoz NM, Leff AR (1987) Distribution of airway contractile response in major resistance airways of the dog. Am J Pathol 129:102-117 
28. Szolcsanyi J, Bartho L (1982) Capsaicin-sensitive non-cholinergic excitatory innervation of the guineapig tracheobronchial smooth muscle. Neurosci Lett 134:247-251

29. Widdicombe JG (1961) Action potentials in vagal efferent nerve fibers to the lungs of the cat. Arch Exp Pathol Pharmacol 214:415-432

30. Widdicombe JG (1961) The activity of pulmonary stretch receptors during bronchoconstriction, pulmonary oedema, ateleclasis and breathing against a resistance. J Physiol (Lond) 159:436-450

31. Widdicombe JG (1966) Action potentials in parasympathetic and sympathetic efferent fibres to the trachea and lungs of dogs and cats. J Physiol (Lond) 186:56-88

32. Yu J, Pisarri TE, Coleridge JCG, Coleridge HM (1991) Responses of slowly adapting pulmonary stretch receptors to reduced lung compliance. J Appl Physiol 71:425-431

Accepted for publication: 18 March 1996 